\title{
Influence of voluntary eye movements on the stepping test.
}

\author{
Pierre-Marie Gagey', Serge Helbert²
}

\begin{abstract}
Background: It is known that a subject's locomotor behavior during the Fukuda-Unterberger stepping test is modified by voluntary rotation of the neck or reflex rotation of the eye following the interposition of a low power prism. Objective: But what are the effects of voluntary eye version? Method: Three parameters of the stepping test were observed in a cohort of 23 rigorously selected subjects, during test executions in five positions of voluntary ocular version. Results: A spin motion, ipsilateral to the ocular version, already apparent for a $2.5^{\circ}$ version that was statistically (Student's t test) significant, were observed. Conclusion: Volunteers or reflexes, version eye movements have the same effect on postural tonic activity.
\end{abstract}

Keywords: Regulation of Postural Tonic Activity; Oculomotricity ; Stepping Test.

\section{INTRODUCTION}

Since J-B Baron's thesis ${ }^{(1)}$, we know that oculomotor muscles play an important role in the non-linear dynamic system that regulates postural tonic activity ${ }^{(2,3)}$. That role was confirmed by the Fukuda-Unterberger test ${ }^{(4)}$, which shows that reflex eye movements effectively modify the regulation of postural tonic activity ${ }^{(5,6)}$. It remains to be confirmed whether voluntary eye movements also act on tone and that that action indeed has the characteristics of non-linear dynamic systems ${ }^{(2)}$.

\section{MATERIALS AND METHODS}

Among 3,138 subjects examined, 23 perfectly normal from a postural point of view were selected using rigorous criteria: age between 18 and 30 years; no history of head trauma or spontaneous loss of consciousness; visual acuity not less than $8 / 10$, no hearing loss less greater than $15 \mathrm{dBA}$ over $4 \mathrm{KHz}$; no static disorder, painless motor points of the anterior tibial muscles and superior and inferior gemellus; no low back pain, otitis, or evolving dental problems; no disturbance of the oculomotor balance; normal and congruent asymmetries of orthostatic posture ${ }^{(7)}$, normal nuchal reflex response to the stepping test ${ }^{(5)}$, and normal postural response to voluntary movement of the eyes in orthostatism ${ }^{(8)}$.

These normal subjects performed the stepping test with their "arms at $45^{\circ}$ from the horizontal" (9), head at rest and jaw in the mandibular posture position ${ }^{(10)}$, and their eyes looking at a point placed 30 centimeters from their eyes successively and randomly at $0^{\circ} ; 2.5^{\circ} ; 5^{\circ} ; 15^{\circ}$ and $30^{\circ}$ to the right of the axis of the primary position. A $30-\mathrm{cm}$-long horizontal rod, whose $1-\mathrm{cm}$ distal end was bent perpendicularly downwards, was inserted into a hole pierced centrally in the visor of a workman's helmet. The subject's entire head and helmet were then covered with a white hood allowing passage of light but preventing him/her from seeing anything in the environment but the bent rod tip. The results of Fukuda ${ }^{(4)}$ parameters were studied: deviation angle (delta, $\Delta$ ), spin angle (sigma, $\Sigma$ ), and, from our sequential analysis, parameter " $a$ " (11), which expresses the work of the subject's abductor muscles during stepping. The same protocol was strictly applied to another cohort of 25 age-matched subjects, who were not selected according to the criteria used for the constitution of the first cohort.

\section{RESULTS}

\section{Spin angle}

The spin angle means, $\Sigma$, for the 23 normal subjects were calculated for each version angle $V$ and the experimental values were plotted: $\Sigma=f(V)$ (figure 1 ). Note that the more the subject turns his eyes to the right, the more the spinning movement occurs to the right. The model smoothing the experimental values is a linear function $\Sigma=0.4 \mathrm{~V}+0.7$ but with a weak coefficient $r^{2}=0.77$, and, in accordance with the expected behavior of a non-linear dynamic system, for low version angles, the slope of the curve is much steeper.

\footnotetext{
Corresponding author: Pierre-Marie Gagey. Address: 240 rue saint jacques 75005 Paris France, pmgagey@gmail.com Phone Number: +33 143295448

1 Institut de Posturologie, Paris, France

Full list of author information is available at the end of the article.

Financial support: The authors declare no external funding.
}

Submission date 02 December 2018; Acceptance date 16 January 2019; Publication date 5 December 2019. 


\section{Deviation angle}

The 23 normal subjects' deviation angle means, delta $(\Delta)$, were calculated for each version angle $\mathrm{V}$, and the experimental values plotted on a graph (figure 2). The more the subject turns his eyes to the right, the more the deviation angle turns to the right.

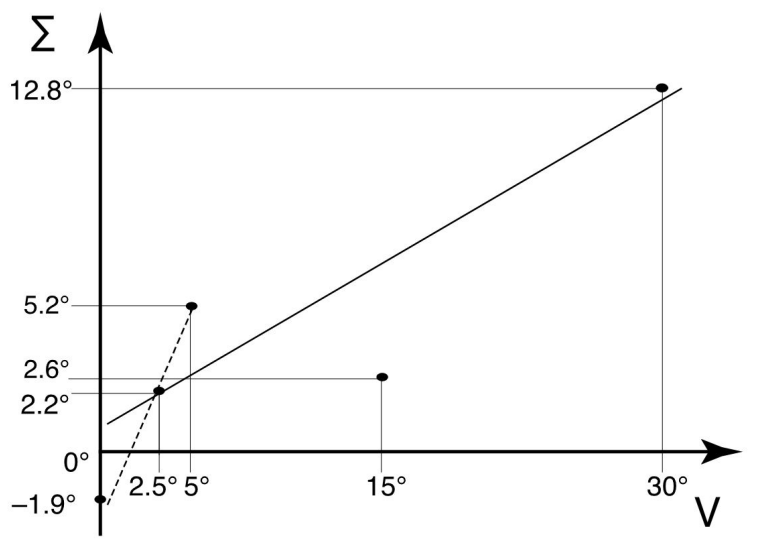

Figure 1 - The spin angle according to the version angle. Note: A subject's spin to the right is assigned a "+" sign, whereas a spin to the left is assigned a " - " sign. Version movements are always oriented to the right of the subject.

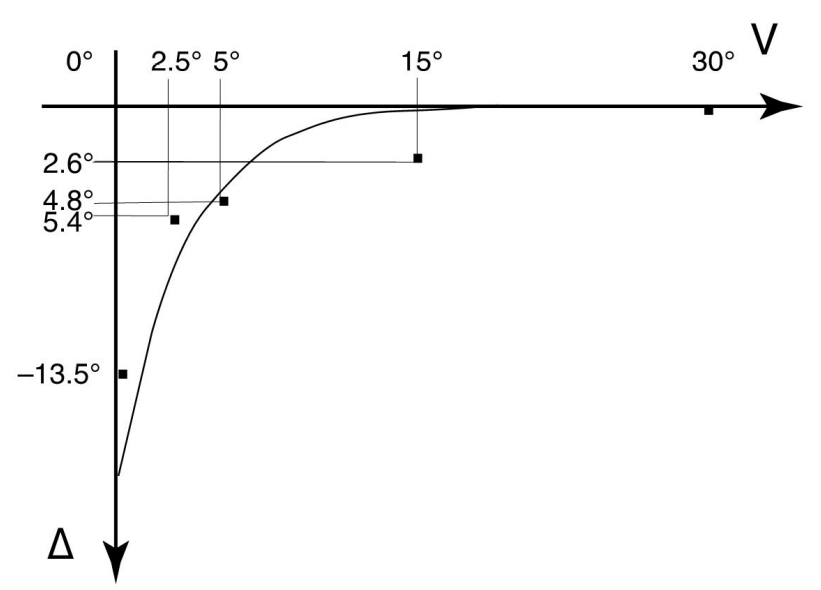

Figure 2 - Deviation angle, delta $(\Delta)$, according to each version angle $V$. Note: A rightward deviation of the subject's gaze is assigned a "+" sign, whereas a leftward deviation is assigned a sign " $-"$ ". Version movements are always oriented to the right of the subject.
The model smoothing the experimental values is an exponential function: $\Delta=-22^{\mathrm{e}-0.3 \mathrm{~V}}$, with $\mathrm{r}^{2}=0.88$. With this $\Delta$ parameter, which is a weak parameter of the stepping test ${ }^{(12)}$, we do not find the expected effect of a non-linear dynamic system, as can be seen with the sigma parameter.

\section{Parameter "a"}

The 23 subjects' mean parameter "a" values were calculated for each version angle and plotted (figure 3 ) on a graph $a=f(V)$. The more the subject turns his eyes to his right, the more he goes to his right by the work of the abductoradductor muscles. For the initial position, the "a" value is -0.11 ("a" values are assigned a negative sign when the abductor-adductor muscles push the subject to his left). For a $30^{\circ}$ version angle to the right, the "a" value is only -0.038 . The model smoothing experimental values is an exponential function: $a=-0.09^{\mathrm{e}-0.035 \mathrm{~V}}$, whose coefficient $r^{2}=0.69$. We do not find the expected effect of a non-linear dynamic system.

\section{Importance of selection}

Variations in the deviation angle versus the version angle are compared in Table 1 between the selected cohort and the unselected cohort.

\section{DISCUSSION}

The results of this study confirm the now well-known role of eye movements in the regulation of postural tonic activity. Regardless of whether those movements are a reflex or voluntary, they lead to the same response to the stepping test: a rotation towards the side of the active oculomotor muscles.

These results are consistent with the properties of the non-linear dynamic systems of which the upright postural system $^{(2,3)}$ is part: compared to a large version angle variation, a small variation causes a proportionally much larger effect on the spin angle. This finding holds our attention-despite it not being statistically significant-because of recent data on the role of the directing eye on the organization of bodily asymmetries ${ }^{(13)}$. That a minimal modification of the directing eye angle can affect the regulation of postural tonic

Table 1 - Deviation angle as a function of the version angle, in both cohorts.

\begin{tabular}{|c|c|c|c|c|c|c|}
\hline \multirow{3}{*}{ Version angle, $\mathrm{V}$} & \multicolumn{6}{|c|}{ Deviation angle, $\Delta$} \\
\hline & \multicolumn{3}{|c|}{ Selected normal subjects } & \multicolumn{3}{|c|}{ Unselected subjects } \\
\hline & m & $\sigma$ & $\mathbf{t}$ & $\mathrm{m}$ & $\sigma$ & $\mathbf{t}$ \\
\hline $0^{\circ}$ & $-13^{\circ}$ & 26 & & $-3^{\circ}$ & 11 & \\
\hline $2.5^{\circ}$ & $-5^{\circ}$ & 13 & 1.29 & $-4^{\circ}$ & 13 & 0.4 \\
\hline $5^{\circ}$ & $-5^{\circ}$ & 11 & 1.45 & $-3^{\circ}$ & 10 & 0.1 \\
\hline $15^{\circ}$ & $-3^{\circ}$ & 12 & 1.78 & $-2^{\circ}$ & 15 & 0.1 \\
\hline $30^{\circ}$ & $0^{\circ}$ & 10 & 2.28 & $-4^{\circ}$ & 19 & 0.3 \\
\hline
\end{tabular}

Note: Mean $(\mathrm{m})$, standard deviation $(\sigma)$ and Student's t. 


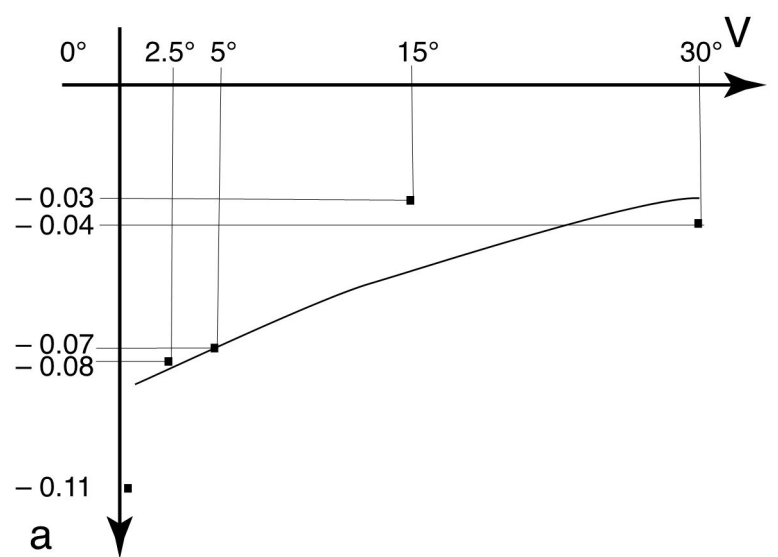

Figure 3 - Evolution of the "a" parameter according to the version angle. Note: The "a" values are assigned a negative sign when the abductor-adductor muscles push the subject to his left.

activity upholds the hypothesis that there is a "Law of Body Asymmetry"(13).

Finally, it is important to emphasize the importance of selecting normal subjects for this type of experiment (Table 1). Out of 3,000 subjects seen, only 23 were selected who provided the results presented herein. The same tests performed by 25 unselected subjects did not yield the same results at all. Andre Thomas had previously highlighted the great lability of the tonic phenomena ${ }^{(14)}$, which prevented him from seeing their organization.

\section{AUTHOR'S CONTRIBUTIONS:}

All authors contributed equally to the elaboration of the manuscript.

\section{CONFLICT OF INTEREST:}

The authors declare no conflicts of interest.

\section{AUTHORS DETAILS}

2 Centre de Formation Posturologie Orthèses, Paris, France

\section{REFERENCES}

1. Baron J. Muscles moteurs oculaires, attitude et comportement locomoteur des vertébrés: Paris; 1955.

2. Poincaré $H$. Les méthodes nouvelles de la mécanique céleste. Paris: Gauthier-Villars; 1893.

3. Gagey P, Martinerie J, Pezard L, Benaim C. L'équilibre statique est contrôlé par un système dynamique non-linéaire. Ann Oto-Laryngol, . 1998;115:161-8.

4. Fukuda T. The stepping test. Two phases of the labyrinthine reflex. Acta Otolaryngol (Stockh). 1959;50(2):95-108.

5. Ushio N, Matsuura K, Hinoki M, Baron J, Gagey P. Deux phases de réflexe dans l'équilibre provoquées par les propriocepteurs des muscles oculaires. Analyse à l'aide du test de piétine-ment de Fukuda et du test de réflexe orthostatique. Agressologie. 1975;16(D):39-52.

6. Gagey P. The law of the canals and postural clinic. MTPRehabJournal. 2016;14:324-30.

7. Gagey P, Asselain B, Ushio N, Baron J. Les asymétries de la posture orthostatique sont elles aléatoires? Agressologie. 1977;18.(2):277-83.

8. Gagey P. L'examen clinique postural . Agressologie. 1980;21(E):125-42.

9. Delwaide P, Figiel C, Richelle C. Effects of postural changes of the upper limb on reflex transmission in the lower limb. J Neurol Neurosurg Psychiat 1977;40(6):616-21.

10. Meyer J, Baron J. Mandibular dynamics and tonic postural activity. Biochemical Views. 1979.

11. Gagey P, Debruille O. Analyse séquentielle du test de piétinement. Son application à l'étude du réflexe nucal. Approche théorique. . Agressologie. 1979;20(B):125-6,

12. Weber $B$, Gagey $P$, Noto $R$. La répétition de l'épreuve modifie-t'elle l'exécution du test de Fukuda? Agressologie. 1984;25:1311-14.

13. Helbert S. Lateralities and Asymmetries of the Orthostatic Posture. Manual therapy posturology and rehabilitation journal. 2016;14:379-89.

14. Thomas A. Équilibre et équilibration. Paris: Masson; 1940. 